\title{
ACUTE PROPTOSIS IN RELATION TO ACTIVATED PROTEIN C RESISTANCE: A CASE REPORT
}

\author{
MARIE COMER and NIKHIL C. KAUSHIK \\ Wrexham
}

\begin{abstract}
SUMMARY
Activated Protein $\mathrm{C}$ resistance is a recently described clotting disorder, accounting for several previously undiagnosed thrombophilic states. Initially this defect had been associated with leg vein thromboses, but it is now recognised that other vascular beds are also prone to clotting in this disorder.

We report a case of acute proptosis in a patient with Activated Protein $\mathrm{C}$ resistance, due to cavernous sinus thrombosis.
\end{abstract}

Undiagnosed clotting disorders are quite common. Normal clotting studies in patients with recurrent thrombosis often remain a diagnostic mystery. In 1993 Dahlback and colleagues ${ }^{1}$ described a previously unrecognised resistance to the anticoagulant response of Activated Protein C. Activated Protein C resistance is particularly common in young patients presenting with recurrent thrombosis. There is often a positive family history, and leg veins appear particularly predisposed to clotting in this disorder. ${ }^{1}$

We describe a case of acute proptosis, due to cavernous sinus thrombosis, in a patient with Activated Protein $\mathrm{C}$ resistance.

\section{CASE REPORT}

A 32-year-old Caucasian man had a 10 year history of an undiagnosed thrombophilic state. His first episode was of superficial thrombophlebitis of the legs; 9 years ago he had a deep vein thrombosis and pulmonary embolism; 5 years. ago he developed superficial thrombophlebitis of the buttocks, and since then has had recurrent episodes of superficial thrombophlebitis of the legs. His thrombophilic state had remained undiagnosed. As a consequence, he was on long-term warfarin. There is no history of clotting disorders in his family.

Correspondence to: Nikhil C. Kaushik, Department of Ophthalmology, Wrexham Maelor NHS Trust Hospital, Croesnewydd Road, Wrexham, Clwyd LL13 7TD, UK.
He developed an incarcerated diaphragmatic hernia, requiring a transabdominal surgical repair. Warfarin was discontinued perioperatively, and recommenced following surgery. However, 12 days after his operation he developed haematuria, and warfarin was again stopped.

Five days later he developed a sudden and intensely painful left protosis. The clinical appearance was of a tense non-pulsatile left orbital swelling, with considerable engorgement of veins around the left orbit (Fig. 1). There was marked conjunctival chemosis and eye movements were extremely restricted. The patient was apyrexial. A clinical diagnosis of cavernous sinus thrombosis was made and intravenous heparin was started immediately, with a dramatic and rapid resolution of the orbital swelling. Intravenous acetazolamide was adminis-

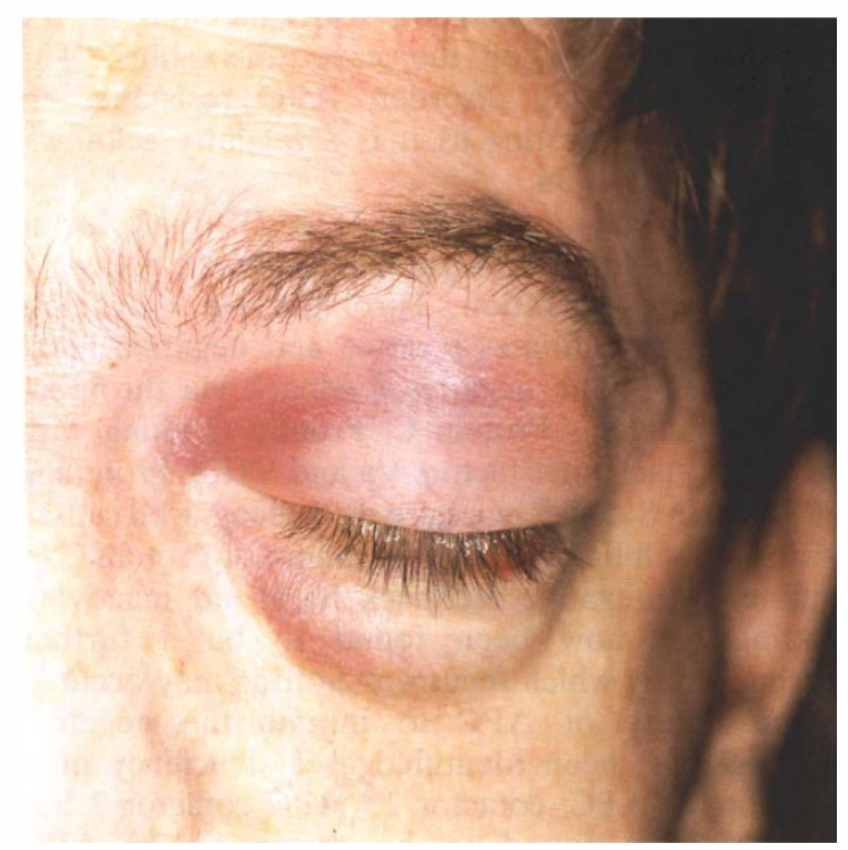

Fig. 1. Proptosed left eye with congested soft tissue and engorged veins around the orbit. 
tered to reduce intraocular pressure. A CT scan showed left proptosis with swelling of the extraocular muscles and enhancement in the region of the cavernous sinus suggestive of cavernous sinus thrombosis.

Overnight the proptosis resolved completely, but he demonstrated an afferent pupillary defect with no perception of light in the left eye, indicative of acute optic nerve infarct. Over the next few days the bruising and subconjunctival haemorrhage settled but he did not regain any visual perception in the left eye.

The patient had a further episode of superficial thrombophlebitis of the legs, and an episode of digital ischaemia of one foot.

Results of investigations for a thrombophilic state were all within normal range: antithrombin III activity $99 \%$ (ref. range 80-155), Protein C activity $71 \%$ (ref. range $65-165$ ) and Protein S activity $68 \%$ (ref. range 70-150). Anticardiolipin antibodies were normal. Serum complement was normal. The Activated Protein $\mathrm{C}$ Resistance (APCR) test was performed. A ratio of 1.72 (normal range >2.03) suggested Activated Protein C (APC) resistance. The rest of the family were screened for APC resistance, and were all normal (ratio $>4$ ).

The patient will remain on lifelong anticoagulation with warfarin.

\section{DISCUSSION}

This case demonstrates a cavernous sinus thrombosis, as a result of a clotting disorder; more commonly this presents in association with infection of the drainage territory of the cavernous sinus. The underlying clotting disorder, APC resistance, is particularly interesting as it is a recently acknowledged phenomenon.

In the coagulation cascade (Fig. 2), tissue factor initiates both the intrinsic and the extrinsic pathways of thrombin generation. Thrombin not only clots fibrinogen but initiates positive and negative feedback systems. The negative feedback via thrombomodulin activates Protein C. Protein $\mathrm{C}$ along with Protein S inactivates factors Va and VIIIa. Protein C and Protein $\mathrm{S}$ deficiencies are well-recognised causes of thrombophilia. ${ }^{2}$ However, a failure of Protein C to initiate the negative feedback loop and inactivate clotting has now been found to be a further mechanism by which recurrent clotting may occur. ${ }^{1}$

The failure of APC to initiate the negative feedback has been identified as a deficiency of a cofactor for APC: cofactor $2 .^{3}$ APC cofactor 2 has recently been found to be factor V. In APC resistance the factor $\mathrm{V}$ molecules are abnormal. ${ }^{4}$ These factor $\mathrm{V}$ molecules have normal procoagulant activity but are defective in initiating their own destruction by APC. The abnormality of the factor V

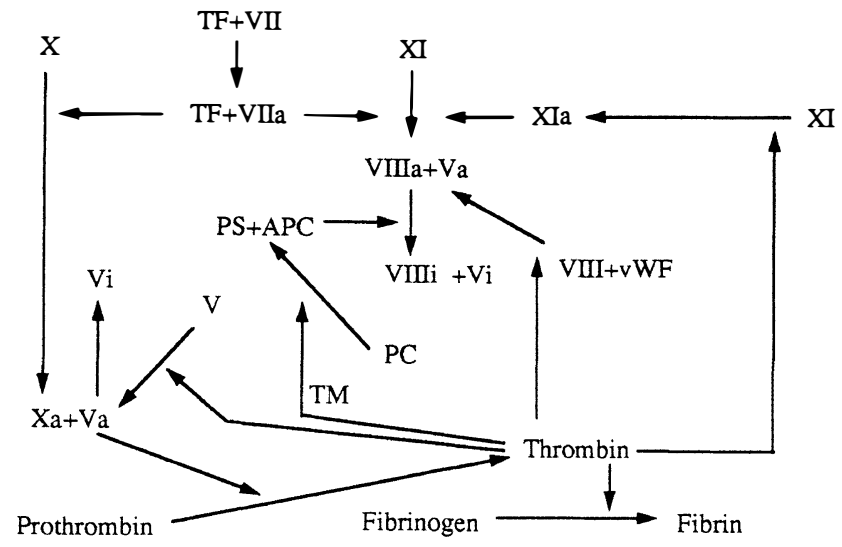

Fig. 2. The clotting cascade. Note the negative feedback loop: Thrombomodulin (TM) activates Protein C (PC), which is converted to Activated Protein $C$ (APC). With Protein S (PS), APC inactivates factor Va and factor VIIIa. $T F$, tissue factor; $v W F$, von Willebrand factor; Vi, inactivated factor V; VIIIi, inactivated factor VIII.

molecule resides in a point mutation of the factor $\mathrm{V}$ gene such that glutamine is substituted for arginine, and the resulting change in molecular conformation and binding properties renders it resistant to inactivation by APC. ${ }^{5}$ This mutation is now referred to as Factor V Leiden.

Although APC resistance has mostly been described in association with leg vein thrombosis, other vascular beds are also prone to thrombosis in this disorder. Recently a case of central retinal vein occlusion has been described in a patient with APC resistance. ${ }^{6}$

In our patient the cavernous sinus thrombosis was associated with APCR. In patients with clotting of vascular beds other than leg veins the possibility of clotting disorder including APC resistance should be considered.

\section{CONCLUSION}

We describe the case of a young man with recurrent thrombosis, presenting with acute proptosis due to cavernous sinus thrombosis, who was subsequently found to have Activated Protein $C$ resistance. This is an interesting, recently described mechanism which is proving common in young patients with hitherto undiagnosed thrombophilic states. We believe this is the first report of a patient with clotting in the deep venous system of the brain in association with Activated Protein $\mathrm{C}$ resistance. A degree of awareness and vigilance for this newly described clotting disorder may yield a diagnosis in the young patient with thrombosis in the eye or orbit.

Key words: Activated Protein C resistance, Cavernous sinus thrombosis, Proptosis.

\section{REFERENCES}

1. Dahlback B, Carlsson M, Svensson PJ. Familial throm- 
bophilia due to a previously unrecognised mechanism characterised by poor anticoagulant response to activated protein $C$ : prediction of a cofactor to activated protein C. Proc Natl Acad Sci USA 1993;90:1004-8.

2. Hirsh J, Raskob GE. Epidemiology and pathogenesis of venous thrombosis. J Am Coll Cardiol 1986;8: 104B-13B.

3. Koster T, Rosendaal FR, de Ronde H, Briet E, Vandenbroucke JP, Bertina RM. Venous thrombosis due to poor anticoagulant response to activated protein C: Leiden thrombophilia study. Lancet 1994;342: $1503-6$
4. Dahlback B, Hildebrand B. Inherited resistance to activated protein $\mathrm{C}$ is corrected by anticoagulant activity found to be a property of factor V. Proc Natl Acad Sci USA 1994;91:1396-400.

5. Voorberg J, Roelse J, Koopman R, et al. Association of idiopathic venous thrombo-embolism with single point mutation at Arg506 of factor V. Lancet 1994;343: 1535-6.

6. Dhote R, Bachmeyer C, Horellou MH, Toulon P, Christoforov B. Central retinal vein thrombosis associated with resistance to activated protein C. Am J Ophthalmol 1995;120:388-9. 